\title{
Fruit Yield and Quality as Related to Flushes of Bearing Shoots in Litchi
}

\author{
Jer-Chia Chang ${ }^{1}$ \\ Section of Crop Improvement, Miaoli District Agricultural Research and Extension Station, Miaoli, \\ Taiwan 363, Republic of China \\ Tzong-Shyan Lin ${ }^{1}$ \\ Department of Horticulture, National Taiwan University, No. 1, Sec. 4, Roosevelt Road, Taipei, \\ Taiwan 106, Republic of China
}

\begin{abstract}
AdDitional IndEX words. Litchi chinensis Sonn., girdling, leaf, fruit retention, fruit cluster
Abstract. The goal of this study was to document the relationship between fruit growth patterns and flushing number in litchi (Litchi chinensis Sonn. cv. 73-S-20). The impact of flush number on fruit retention, fruit quality, and leaf efficiency (g fruit FW produced per unit of leaf area at harvest) was assessed in field-grown 6-year-old trees by adjusting the number of flushes per bearing shoot through girdling at two fruit developmental stages. The cumulative fruit growth was sigmoidal. The greatest fruit relative growth rate (RGR) occurred during 3 to 5 weeks after full

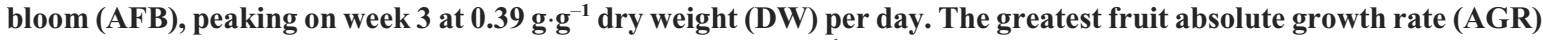
occurred during weeks 8 to 11 , peaking on week 11 at $0.16 \mathrm{~g} \cdot \mathrm{d}^{-1} \mathrm{DW}$. Fruit retention was sensitive to girdling applied during week 3. Most fruit dropped on branches with $\leq$ two flushes, whereas fruit continued to develop on branches with three flushes and on the controls. There was a gradual loss of fruit when the girdling was applied during week 8. The number of fruit retained on branches with two and three flushes was similar to the controls. At harvest, regardless of the time of branch girdling, fruit yield and quality increased with increasing number of flushes; shoots with three flushes were similar to ungirdled controls. Leaf efficiency on branches girdled during week 3 was inferior to that girdled during week 8 . All treatments had similar leaf efficiency when branches were girdled during week 8 . On the other hand, girdling treatment applied during week 3 resulted in variable leaf efficiency among treatment, indicating that fruit were utilizing reserves in bearing shoots. We concluded that bearing shoots of ' $73-\mathrm{S}-20$ ' litchi trees require a minimum number of three flushes for adequate fruit production.
\end{abstract}

Poor fruit set in litchi (Litchi chinensis Sonn.) generally is caused by a failure of pollination and fertilization, a shortage of carbohydrates from overcast weather, or competition between fruit and vegetative growth (Galan-Sauco and Menini, 1989; Menzel, 1984; Mustard et al., 1953; Yuan and Huang, 1993). The relationship between fruit growth and source/sink strength has been demonstrated by trunk girdling and fruit thinning experiments in peach [Prunus persica (L.) Batsch] (Pavel and DeJong, 1993), grape (Vitis vinifera L.) (Kingston and van Epenhuijsen, 1989), and grapefruit (Citrus paradisi Macf.) (Bustan et al., 1996). However, little information is available on litchi.

Carbohydrate accumulation, which may derive from tree reserves, canopy photosynthesis, or photosynthesis by the fruit (Blanke and Lenz, 1989; Hieke et al., 2002a), is essential for fruit development. After girdling and defoliation in 'H1224' litchi trees, Yuan and Huang (1988) observed that initial fruit set increased with increasing leaf area. By girdling and removing different numbers of fruit and leaves from branches, Roe et al. (1997) reported that developing fruit of 'Tai So'

Received for publication 17 Dec. 2007. Accepted for publication 14 Jan. 2008 We would like to thank the Council of Agriculture of Taiwan, Republic of China, for financially supporting this research under Contract No. COA 92AST-1.1.1-FAD-M2.

Ming-Hsien Hsieh, Hong-Peng Lin, and Shu-Yin Li are gratefully acknowledged for their assistance in carrying out the experiments and statistical analysis. Thanks are also extended to Loong-Sheng Chang and Chun-Ta $\mathrm{Wu}$ for their critical comments on an earlier version of this manuscript.

${ }^{1}$ Corresponding author. E-mail: jerchia@mdais.gov.tw and tslin@ntu.edu.tw. depended primarily on current $\mathrm{CO}_{2}$ assimilation from leaves rather than on stored carbohydrates. Applying treatments that consisted of defoliating whole trees or branches, and fruit thinning, Hieke et al. (2002b) further indicated that most of the photosynthates sustaining fruit growth in 'Kwai May Pink' came from current assimilations in the leaf next to the inflorescence. Through investigating the effects of leaf age and location on gas exchange in ' $73-\mathrm{S}-20$ ' litchi, Chang and Lin (2007) also reported that leaf photosynthesis on younger flushes and adjacent to fruit was greater than that on shaded older flushes. These experiments have provided preliminary evidence of the importance of mature leaves adjacent to fruit clusters (i.e., the flushes of the bearing shoot) as the main carbon source throughout fruit growth. Additional support for the role of the bearing shoot as a carbohydrate source came from Menzel (2005), who pointed out that individual branches generally act independently and supply assimilates to fruit only when there is a severe local shortage of fixed $\mathrm{CO}_{2}$. Therefore, it appears that the bearing shoot is the major source of carbohydrates for fruit growth, mainly through leaf $\mathrm{CO}_{2}$ assimilation, but also through its carbohydrate reserves when needed.

The litchi tree produces a number of shoots each year as flushes (Subhadrabandhu and Stern, 2005). In Taiwan, before the winter quiescence, two to three flushes are commonly produced in a fruiting tree after harvest (Chen and Huang, 1994; Huang, 1966; Teng, 1997; Yen and Tien, 1985). This multiple flushing is contrary to the result of Batten and Lahav (1994), who reported that a minimum cycle would be 6 to 8 weeks for flushing and 4 to 6 weeks between flushes; consequently, a 
bearing shoot rarely completes more than two flushes between harvest and flower initiation in Australia. However, the duration and interval of successive flushes in litchi seems to be strongly dependent on the vigor of the tree, orchard management [e.g. pruning (Yen and Tien, 1985)], irrigation, radiation, and temperature (Menzel, 2005; Olesen et al., 2002). Hieke et al. (2002c) reported three flushing cycles in potted 'Wai Chee' litchi that consisted of a mean flushing duration of $20 \mathrm{~d}$ and an interflushing period of $10 \mathrm{~d}$.

Huang (1966) and Olesen et al. (2002) observed the importance of flushing management in terms of the bearing shoot for flowering and fruiting in litchi, and Chang (2004) suggested that poor fruit retention would result from insufficient flushes on the bearing shoot, whereas poor flowering could occur when the bearing shoots produce immature flush and leaves in winter. Based on their study of 'Irwin' mango (Mangifera indica L.), Lin and Li (1997) reported that fruit yield and quality were adequate on bearing shoots, which had two flushes between harvest and quiescence. However, to date, most of the related studies in litchi have focused on the correlation between fruiting and number of leaves or leaf area. Although the results of Hieke et al. (2002b) clearly showed the effects of defoliation of the last flush, previous flush, or all old leaves on yield and fruit weight at harvest on a whole-tree basis in 'Kwai May Pink,' previous studies have not yet provided information on how many flushes on a bearing shoot are required to support fruit production.

Stern and Gazit (2003) proposed that the initial fruit set in litchi might be affected by the fruit growth pattern because of assimilate competition. Our previous work (Chang and Lin, 2004) characterized fruit growth of '73-S-20', an irregular bearing line of 'No Mai Tsz' litchi found in JiJi, Nantou, central Taiwan (lat. $23^{\circ} \mathrm{N}$ ) (Yen et al., 1984) and documented that during the peak periods of the fruit, relative growth rate (RGR in dry weight) and fruit absolute growth rate (AGR in dry weight), fruit set, and quality per cluster would decline if a bearing shoot had insufficient mature flushes and leaves to support the rapid fruit growth.

We hypothesized that a bearing shoot comprised of three flushes and its carbohydrate reserves are essential for adequate cluster production. The objectives of the this study were to characterize fruit growth patterns and to modify source and sink relationships by branch girdling at two fruit development stages to determine the number of flushes required by a bearing shoot to support fruit cluster development in '73-S-20' litchi. Fruit retention, fruit quality, and leaf efficiency (g fruit FW produced per unit of leaf area at harvest) were also evaluated. The results reported here are useful for documenting the sink/source relationship during fruit growth and for developing strategies on canopy management in terms of enhancing fruit production in litchi.

\section{Materials and Methods}

Plant material. The experiments were conducted on 6year-old '73-S-20' trees in Fengyuan, Changhua County, central Taiwan (lat. $24^{\circ} \mathrm{N}$ ). Trees were spaced at $5 \times 5 \mathrm{~m}$. The first wave of male flowers appeared on 10 Mar. 2003. Two hives of honeybees (Apis mellifera Linn.) (15,000 bees per hive) were immediately moved into the orchard to facilitate pollination. Female flowers full bloomed on 26 Mar. 2003 (the day was served as week 0 after full bloom, AFB), and on 8 Apr. 2003 (week 2), 12 trees were selected and randomly separated into three groups (four trees per group) for three experiments.

Fruit Growth CURVe. On 8 Apr. 2003 (week 2), 480 fruit on 32 fruiting shoots were selected from four trees and were arranged in a completely randomized design. Twenty to 30 fruit were sampled weekly until 18 June. The sampled fruit were immediately placed on ice and delivered to Miaoli District Agricultural Research and Extension Station in central Taiwan (Kung-Kuan, Miaoli; lat. $23^{\circ} \mathrm{N}$ ). Fresh and dry weight (oven dried at $65^{\circ} \mathrm{C}$ ) of the fruit, pericarp (skin), seed, and aril were weighed, and total soluble solids (TSS) of the aril was determined using a digital refractometer (Plate PR-101; Atago, Tokyo).

Fruit RGR was calculated as follows:

$\operatorname{RGR}\left(\mathrm{g} \cdot \mathrm{g}^{-1} \mathrm{DW}\right.$ per day $)=\left(\mathrm{DW}_{2}-\mathrm{DW}_{1}\right) /\left[\mathrm{DW}_{1} \times\left(\mathrm{T}_{2}-\mathrm{T}_{1}\right)\right]$

where DW is dry weight (in grams) and T is time (in days)

Fruit AGR was calculated as follows:

$$
\operatorname{AGR}\left(\mathrm{g} \cdot \mathrm{d}^{-1} \mathrm{DW}\right)=\left(\mathrm{DW}_{2}-\mathrm{DW}_{1}\right) /\left(\mathrm{T}_{2}-\mathrm{T}_{1}\right)
$$

EFFECTS OF FLUSH NUMBER ON FRUIT RETENTION AND FRUIT QUALITY. Two girdling experiments were conducted on $15 \mathrm{Apr}$. (week 3 AFB) and on 18 May (week 8) 2003, and four trees and 72 branches were used in each experiment. The branches nested within tree. Eighteen bearing branches were labeled within each tree and were randomly assigned as nested design to six treatments with three replicates for each treatment. Each tree served as a main experiment unit (regarded as the first factor with random effect) and each shoot served as a subexperiment plot (regarded as the second factor with fixed effect). Each bearing shoot (1.0-1.5 cm in diameter) consisted of three mature flushes that had been produced in succession (the first flush was the oldest and was positioned at the base; the third flush was the youngest and was located at the terminal position) between harvest and quiescence of the previous year (Fig. 1). The clusters had 30 to 33 fruit $(0.15 \mathrm{~g})$ by week 3 and 19 to 21 fruit $(4.2 \mathrm{~g})$ by week 8 . The equivalent number of flushes was adjusted to $0,0.5,1,2$, and 3 (around $0,12,25,50$,

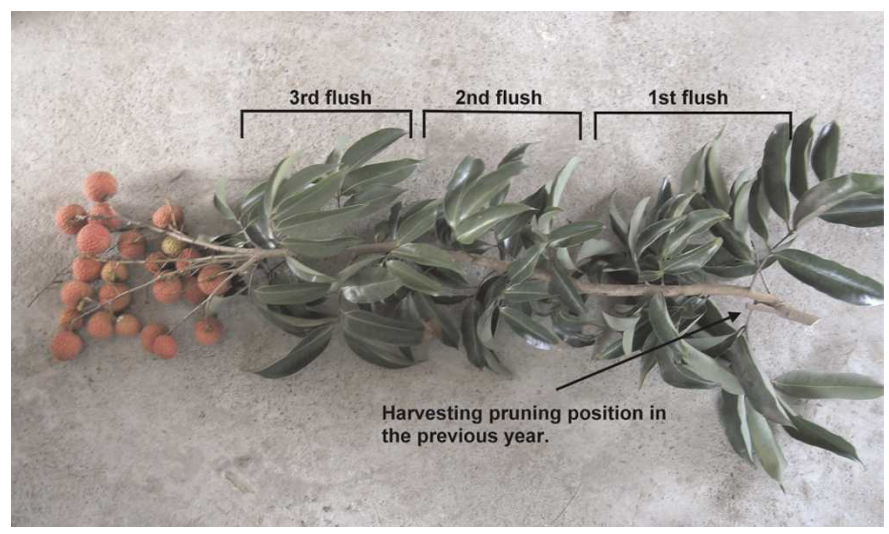

Fig. 1. A bearing shoot with fruit cluster consisted of three mature flushes that had been produced in succession between harvest and quiescence in the previous year in '73-S-20' litchi. 
and $75 \mathrm{~cm}$ of length from girdling to fruit cluster, respectively) by girdling, which removed $0.5 \mathrm{~cm}$ of bark at the base of the flush, and an ungirdled treatment served as the control. The number of fruit retained and the percentage of fruit set were calculated weekly, and fruit clusters were harvested on 18 June 2003 (week 12). Total weight, single fruit weight, and TSS were measured as described above.

LEAF EFFICIENCY. The number of leaves per flush was determined on 15 Apr. (week 3 AFB) and 18 May (week 8 AFB) 2003, respectively. At harvest, the leaf area of each flush was measured with a leaf area meter (LI-3000; LI-COR, Lincoln, NE). Leaf efficiency ( $g$ fruit FW produced per unit of leaf area at harvest) was calculated as follows:

Leaf efficiency $=$

(fruit weight at harvest)/(leaf area retained per bearing shoot)

Statistical analysis. Data were analyzed by mixed model analysis of variance in a nested design using SAS (release 6.12; SAS Institute, Cary, NC). Because the branches nested within a tree, each shoot was a subexperiment plot and each tree was a main experiment unit. The model included the fixed effects of treatment and the random effect of both the tree and the interaction of tree $\mathrm{x}$ treatment. Because of the nested design, the variation of replicates (tree $\times$ treatment) interaction was used as the error term for testing effect of treatment. Proc Mixed procedure was performed to examine the data with Fisher's least significant difference test at $P \leq 0.05$. Because of lack of plot effect, only treatment effects are presented.

\section{Results}

Fruit Growth CURVE. Fruit growth was sigmoidal, and the fruit took 12 weeks to complete development (Fig. 2). In the first 6 weeks, the majority of fruit biomass was gained from the growth of the pericarp and seed (around 20\% of aborted seed); by week 9 AFB, this had slowed down. Aril weight was immeasurable until the week 6 , but it was a major contribution to fruit weight accumulation (particularly between week 8 and week 12). Fresh weight continuously increased in the fruit until harvest, whereas dry weight slowed down after week 11 . The TSS during week 7 was $\approx 10 \%$, increasing markedly to $19.2 \%$ between week 8 and week 11. At harvest (week 12), the average fruit weighed $18.6 \mathrm{~g}$ fresh weight $(\mathrm{FW}), 4.1 \mathrm{~g}$ dry weight (DW), and had a TSS of $19.3 \%$ (Fig. 2, A and B).

RGR declined over time, with a maximum value of $0.39 \mathrm{~g} \cdot \mathrm{g}^{-1}$ DW per day, occurring in week 3 (Fig. 3A). The peak AGR, with a maximum value of $0.16 \mathrm{~g} \cdot \mathrm{d}^{-1} \mathrm{DW}$, occurred between weeks 10 and 11 (Fig. 3B).

EFFECTS OF FLUSH NUMBER ON FRUIT RETENTION AND FRUIT QualiTy. Across the two girdling experiments, there was a steady decline in percentage of fruit retention and quality as the number of flushes per bearing shoot declined (Table 1). Fruit retention was sensitive to girdling applied during week 3 (Fig. 4A). Virtually all of the fruit dropped within 1 to 2 weeks when 0.0 to 0.5 flushes were retained, about two-thirds of the fruit dropped in branches with only one flush, and one-third of fruit were lost with two flushes. Few fruit were subsequently lost from the branches after this initial period. In contrast, fruit

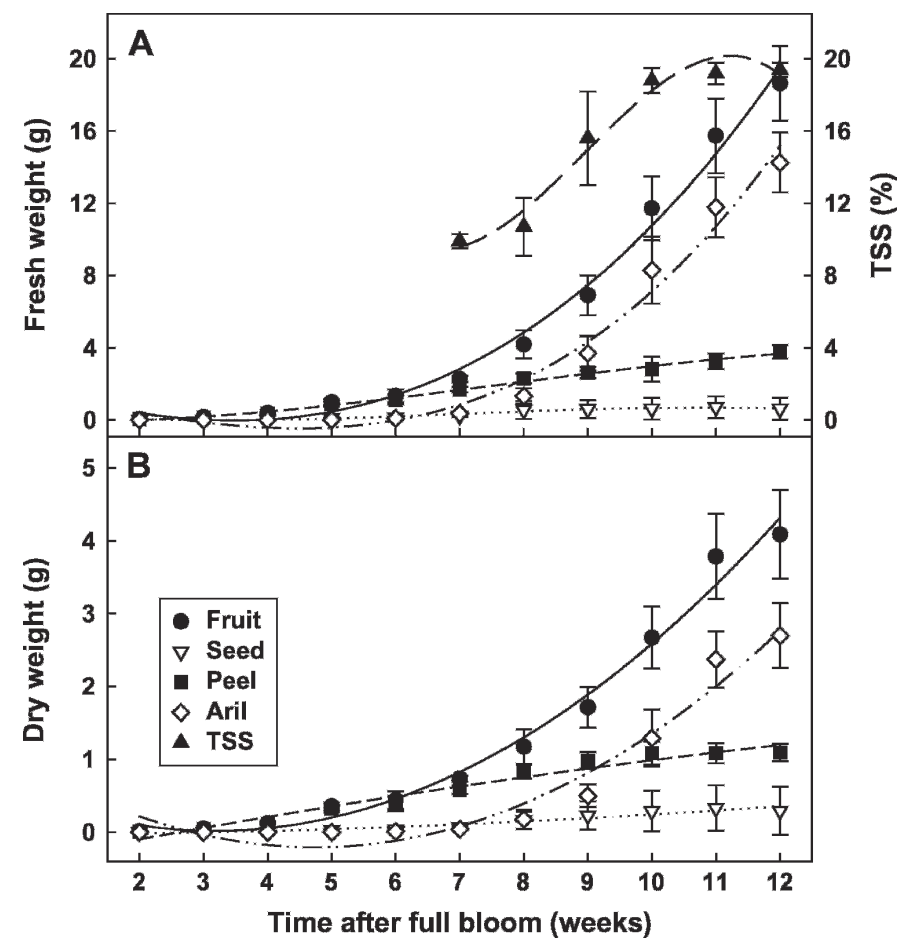

Fig. 2. Changes of (A) fresh weight and total soluble solids (TSS) and (B) dry weight in '73-S-20' litchi fruit. Each value represents the mean \pm SE of 20 to 30 fruit. Regression for fresh weight is $=7.5 \mathrm{x}^{3}+0.1 \mathrm{x}^{2}-1.2 \mathrm{x}+2.1, \mathrm{r}^{2}=0.99$; seed is $=-3.2 \mathrm{x}^{3}+0.1 \mathrm{x}^{2}-0.3 \mathrm{x}+0.5, \mathrm{r}^{2}=0.9678$; peel TS $=-3.4 \mathrm{x}^{3}+0.1 \mathrm{x}^{2}-0.1 \mathrm{x}-0.01$, $\mathrm{r}^{2}=0.99 ;$ aril TS $=0.01 \mathrm{x}^{3}-0.02 \mathrm{x}^{2}-0.7 \mathrm{x}+1.7, \mathrm{r}^{2}=0.98 ;$ and TSS is $=-0.2 \mathrm{x}^{3}+$ $6.2 \mathrm{x}^{2}-51.7 \mathrm{x}+148.0, \mathrm{r}^{2}=0.97$. Regression for dry weight $\mathrm{TS}=0.1 \mathrm{x}^{2}-0.4 \mathrm{x}+$ $0.6, r^{2}=0.99$; dry seed TS $=2.5 \mathrm{x}^{2}+3.3 \mathrm{x}-0.03, \mathrm{r}^{2}=0.93$; dry peel TS $=$ $0.003 \mathrm{x}^{2}+0.2 \mathrm{x}-0.4, \mathrm{r}^{2}=0.96$; and dry aril TS $=0.1 \mathrm{x}^{2}-0.5 \mathrm{x}+1.1, \mathrm{r}^{2}=0.96$.

continued to develop on the branches with three flushes and on the controls (similar retention at harvest). When the girdling treatment was applied during week 8 , there was a more gradual preharvest fruit drop (Fig. 4B). The 0 flush treatment had lost all fruit (20) before harvest; the 0.5 flushes, two-thirds of fruit; and one flush, one-half of fruit. The branches with two flushes and three flushes were similar to the controls in terms of number of fruit. Total fruit weight, average fruit weight, and TSS also declined with decreasing number of flushes. At harvest, regardless of the time of girdling, total fruit weight, average fruit weight, and TSS increased when the number of flushes per bearing shoot increased from 0.5 to 3 ; shoots with three flushes were similar to the ungirdled controls (Table 1).

LEAF EFFICIENCY. A well-developed bearing shoot with three flushes had 1626 to $1676 \mathrm{~cm}^{2}$ leaf area. The treatments had similar leaf efficiency when girdled during week 8 (about 0.18 $\mathrm{g} \mathrm{FW} \cdot \mathrm{cm}^{-2}$ ), but increased with increasing number of flushes when girdled during week $3\left(0.03-0.17 \mathrm{~g} \mathrm{FW} \cdot \mathrm{cm}^{-2}\right)$. However, leaf efficiency on branches girdled during week 3 was inferior to that girdled during week 8 . For the three flushes of shoot in both girdling treatments, the leaf efficiency was 0.17 to $0.18 \mathrm{~g} \mathrm{FW} \cdot \mathrm{cm}^{-2}$ (Table 1$)$.

\section{Discussion}

The fruit of '73-S-20' showed a sigmoidal growth pattern over 12 weeks. Joubert (1986) classified the growth of 'Mauritius' litchi into three stages: the growth of the pericarp and the seeds, which lasts 5 to 7 weeks; the maturation of the 


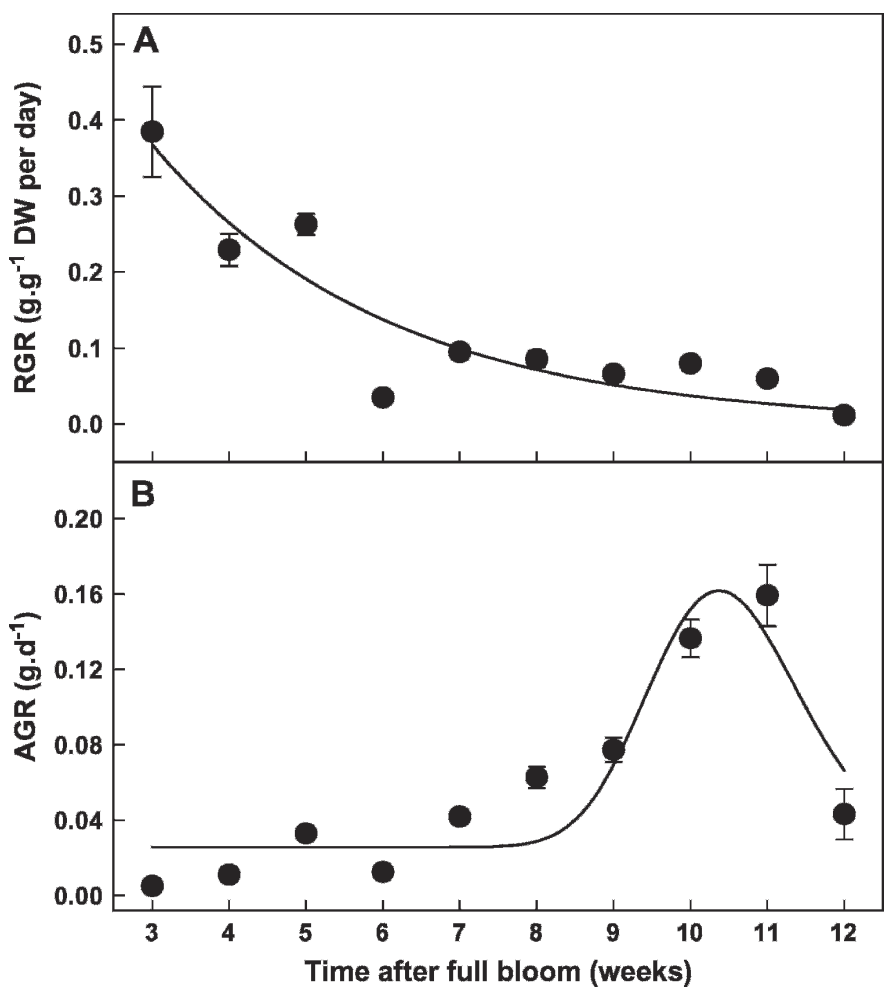

Fig. 3. Changes of (A) relative growth rate (RGR) and (B) absolute growth rate (AGR) in '73-S-20' litchi fruit (dry weight). Each value represents the mean \pm SE of 20 to 30 fruit. Regression for $\mathrm{A}$ is $\mathrm{Y}=0.9827^{*} \exp (-0.3277 \mathrm{X})\left(\mathrm{R}^{2}>\right.$ $0.97 ; P<0.01)$; and $\mathrm{B}$ is $\mathrm{Y}=0.1384 * \exp \left[-0.5 *\{\ln (\mathrm{X} / 10.1182) / 0.1577\}^{2}\right]$ $\left(\mathrm{R}^{2}>0.97 ; P<0.01\right)$.

cotyledons and the initial growth of the aril, which lasts 2 to 3 weeks; and finally, the rapid growth of the aril, which lasts for 5 to 7 weeks. He reported that the greatest increase in fruit weight occurred during the third stage, which we also found. The aril appeared after week 6 AFB and began to grow rapidly once the embryo and cotyledons had fully grown (normal seed) or shriveled (chicken tongued). The aril developed most rapidly from week 8 to week 11 . The TSS had already plateaued by week 11, which is consistent with our previous results (Chang and Lin, 2004).

The greatest fruit RGR in '73-S-20' occurred during week 3. This growth pattern is similar to that in peach (DeJong and Goudriann, 1989) and is consistent with earlier observations by Chang and Lin (2004). Although the mean size of the fruit and fruit AGR are small (sink size) at this stage, the actual strength of the sink may be high, as estimated by Hieke et al. (2002a) on the basis of the expected high respiration (sink activity). The development of young fruit occurs concurrently with vigorous root growth (Yuan and Huang, 1993); consequently, a large amount of assimilate is required to support both vegetative and reproductive growth during this period. From week 8 to 11 , fruit respiration may have declined markedly (Hieke et al., 2002a); however, owing to the rapid accumulation of dry weight, AGR increases and there is likely a strong competition among fruit and other organs for carbohydrate assimilates during this period.

Mustard et al. (1953) divided the physiological abscission of 'Brewster' litchi into two peak phases, with the first phase corresponding to the period when most of the drop occurred in the present study (weeks 2 to 4 ) and the second phase corresponding to the middle-growth period of the present study because of competition for assimilate nutrients. Chang (2004) studied fruit retention of ' $73-\mathrm{S}-20$ ' and found that the main peak of fruit drop occurred from weeks 2 to 5 , similar to the findings in 'Brewster' (Mustard et al., 1953). However, the reasons for fruit abscission during this period have not yet been clearly identified in '73-S-20'. In our experiment, the first girdling of the bearing shoot resulted in a severe fruit drop among treatments in which fewer than three flushes were retained (Fig. 4A). In addition, the number of fruit per cluster of the bearing shoots markedly and rapidly decreased in response to defoliation (from the three flush to the zero flush treatment). This response

Table 1. Effects of flush number and leaf area on cluster yield, fruit quality, and leaf efficiency ( $\mathrm{g}$ fruit FW produced per unit of leaf area at harvest) in '73-S-20' litchi when girdling was performed at week 3 and week 8 after full bloom (AFB).

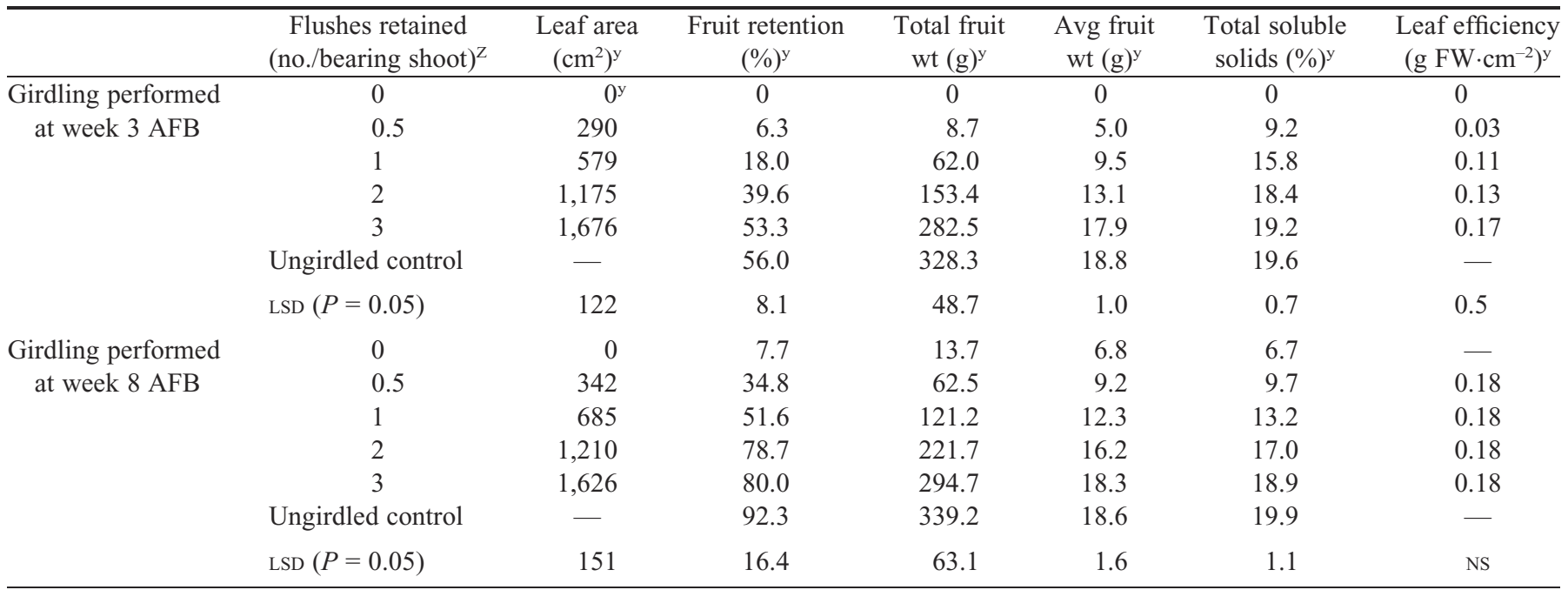

${ }^{\mathrm{Z}}$ Each shoot had the equivalent $0,0.5,1.0,2.0$, or 3.0 leaf flushes, with shoots girdled at different distances from the fruit clusters. Control shoots were not girdled.

${ }^{y}$ Means of 12 bearing shoots nested within four trees for each treatment.

${ }^{\mathrm{Ns}}$ Nonsignificant. 


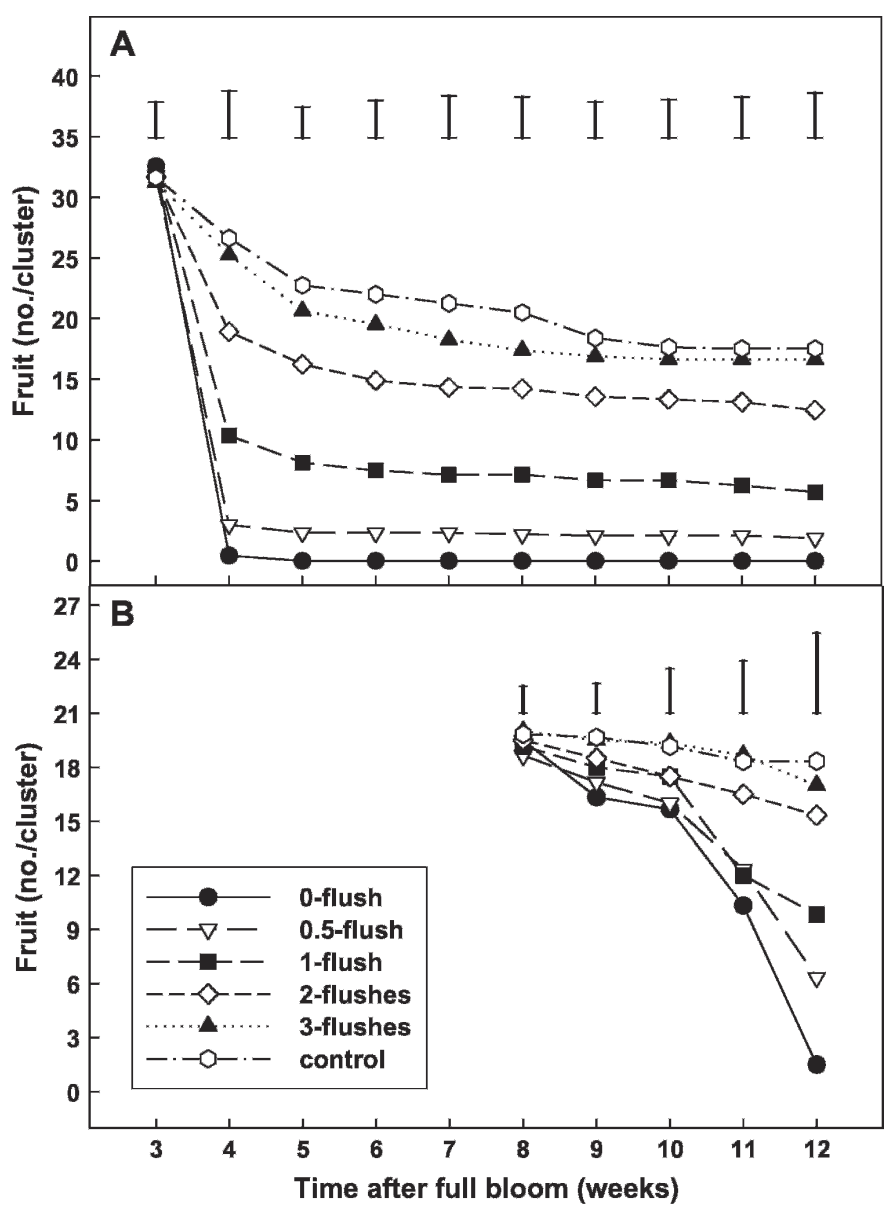

Fig. 4. Effects of flush number on fruit retention in '73-S-20' litchi. Each shoot had the equivalent $0,0.5,1.0,2.0$, or 3.0 leaf flushes, with shoots girdled at (A) week 3 and (B) week 8 AFB at different distances from the fruit clusters Control shoots were not girdled. Each value represents mean of 12 bearing shoots nested within four trees for each treatment. Vertical bars represent LSD at $P=0.05$

was clearly the result of an insufficiency in producing assimilates and a shortage of carbohydrate reserves during weeks 4 to 5 . This tendency resembles the results reported on girdling treatments of 'H-1224' by Yuan and Huang (1988) and on 'Tai So' by Roe et al. (1997), and confirms the importance of the carbon source of the bearing shoot on initial fruit set in litchi. Hieke et al. (2002b) also indicated that young fruit are very sensitive to any shortage in their carbohydrate supply.

There was a second wave of fruit drop that occurred after girdling of the bearing branch during week 8 , but only in branches with fewer than 0.5 or 1 flush per bearing shoot. In contrast, few fruit were lost during this period when their AGR reached the peak in the controls and when the girdled branch had two or three flushes (Fig. 4B). These results demonstrate the importance of a minimum leaf area and the carbohydrate reserves in terms of providing assimilate nutrients to the maturing fruit. At harvest, average fruit weight and TSS increased with increasing flush number and leaf area, regardless of girdling date, indicating that leaf area and carbohydrate reserves influenced fruit retention and fruit quality (Table 1). However, these results differ from those reported by Hieke et al. (2002b), who found that removing all of the leaves at 14 $\mathrm{d}$ before harvest together with girdling the trunk had no effect on yield in 'Bengal' on a whole-tree basis. In addition, the branches used by these authors were 1 to $3 \mathrm{~cm}$ in diameter and the trees used were 12 years old; as such, they are considerably thicker and older than those used in the present study, suggesting that the clusters on these thicker branches were able to draw and access much greater amounts of carbon reserves for sustaining fruit growth.

Fruit retention of shoots with three flushes in both of the present girdling experiments was similar to that of ungirdled controls; however, the consequences of the girdling treatment were more severe when it was carried out during week 3 than during week 8 . Leaf efficiency on branches girdled during week 3 was inferior to that girdled during week 8. Moreover, all treatments had a similar leaf efficiency when the branches were girdled during week 8 , but different efficiencies when girdled during week 3 , indicating that the fruit were able to use carbon reserves in the bearing shoot in addition to the potential compensation of $\mathrm{CO}_{2}$ assimilation through fruiting or girdling (Roe et al., 1997). Fruit at week 3 have been reported especially sensitive to assimilate supply (Hieke et al., 2002b), and after girdling of the branches during week 3 , those branches were effectively isolated from the rest of the branches for the bulk of the fruit developmental period. On the contrary, fruit on shoots of branches girdled on week 8 had access to the reserve in the larger branches for the first 8 weeks of fruit growth. In addition, the leaf efficiency of the three-flush treatment girdling during week $3\left(0.17 \mathrm{~g} \mathrm{FW} \cdot \mathrm{cm}^{-2}\right)$ is similar to the efficiencies of all the treatments when girdling occurred during week $8(0.18$ $\mathrm{g} \mathrm{FW} \cdot \mathrm{cm}^{-2}$ ), also suggesting that even carbohydrate reserves in the fruiting shoots supplied assimilates to the fruit. Reserves in the bearing shoot down to the third flush are used for the initial growth of the fruit, but there is no withdrawal of resources from the other parts of the tree.

\section{Conclusions}

We demonstrated that a bearing shoot with three flushes has sufficient leaf assimilating ability and carbohydrate reserves to support the growth demand for 16 to 18 fruit of satisfactory quality (Fig. 1). Our results indicated that the production of an adequate number of flushes by a bearing shoot, with a sufficient area of mature leaves and carbohydrate reserves, is one of the critical factors determining high fruit retention in litchi.

The results not only confirms the results reported by Roe et al. (1997) that litchi fruit appeared to be mainly dependent on current $\mathrm{CO}_{2}$ assimilation, but also constructs a theoretical basis and provides a potential possibility to increase yield and quality of litchi by manipulating flush growth. Notably, experiments with small branches might have ignored the availability of carbohydrate reserves in trunks and main limbs. Further experiments on whole tree basis will be required to identify the potential status of remote carbohydrate resources, and the relative role of carbohydrates reserves and leaf photosynthesis compensation caused by fruiting/girdling on fruit set and fruit growth in litchi.

\section{Literature Cited}

Batten, D.J. and E. Lahav. 1994. Base temperature for growth processes of lychee, a recurrently flushing tree, are similar but optima differ. Aust. J. Plant Physiol. 21:589-602.

Blanke, M.M. and F. Lenz. 1989. Fruit photosynthesis: a review. Plant Cell Environ. 12:31-46. 
Bustan, A., E.E. Goldschmidt, and Y. Erner. 1996. Carbohydrate supply and demand during fruit development in relation to productivity of grapefruit and 'Murcott' mandarin. Acta Hort. 416:81-88.

Chang, J.C. 2004. Studies on fruit set in 'No Mai Tsz' and 'Yu Her Pau' litchi. National Taiwan University, Taipei, Taiwan PhD dissertation. (in Chinese with English summary).

Chang, J.C. and T.S. Lin. 2004. Growth of developing 'No Mai Tsz' litchi fruit. J. Agr. Assn. China 5:535-550. (in Chinese with English summary).

Chang, J.C. and T.S. Lin. 2007. Gas exchange in litchi under controlled and field conditions. Scientia Hort. 114(4):268-274.

Chen, S.H. and H.Y. Huang. 1994. Studies on the flush growth and panicle formation of litchi, p. 119-129. In: H.S. Lin and L.R. Chang (eds.). Proceedings of a symposium on the practical aspects of some economically fruit trees grown in Taiwan. Taichung District Agricultural Improvement Station. Chunghua, Taiwan (in Chinese with English summary).

DeJong, T.M. and J. Goudriann. 1989. Modeling peach fruit growth and carbohydrate requirements: Re-evaluation of the double-sigmoid growth pattern. J. Amer. Soc. Hort. Sci. 114:800-804.

Galan-Sauco, V. and U.G. Menini. 1989. Litchi cultivation. Plant production and protection paper 83. Food and Agriculture Organization of the United Nations, Rome.

Hieke, S., C.M. Menzel, and P. Ludders. 2002a. Effects of leaf, shoot and fruit development on photosynthesis of litchi trees (Litchi chinensis Sonn.). Tree Physiol. 22:955-961.

Hieke, S., C.M. Menzel, V.J. Doogan, and P. Ludders. 2002b. The relationship between yield and assimilate supply in litchi (Litchi chinensis Sonn.). J. Hort. Sci. Biotechnol. 77:326-332.

Hieke, S., C.M. Menzel, and P. Ludders. 2002c. Shoot development, chlorophyll, gas exchange and carbohydrate in litchi seedlings (Litchi chinensis Sonn.). Tree Physiol. 22:947-953.

Huang, P.C. 1966. Investigation on the growth of new shoots and flower clusters of lychee tree. J. Chinese Soc. Hort. Sci. 12:8-14. (in Chinese with English summary).

Joubert, A.J. 1986. Litchi, p. 233-246. In: S.P. Monselise (ed.). CRC handbook of fruit set and development. CRC Press, Boca Raton, FL. Kingston, C.M. and C.W. van Epenhuijsen. 1989. Influence of leaf area on fruit development and quality of Italia glasshouse table grapes. Amer. J. Enol. Viticult. 40:130-134.

Lin, T.S. and K.T. Li. 1997. Leaf number affects fruit quality in mango, p. 73-84. In: L.J. Chang and R.W. Chen (eds.). Special report: Proceedings of the third symposium on fruit industry competition enhancement. Taichung District Agricultural Improvement Station, Chunghua, Taiwan (in Chinese with English summary).
Menzel, C.M. 1984. The pattern and control of reproductive development in litchi: A review. Scientia Hort. 22:333-345.

Menzel, C.M. 2005. Photosynthesis and productivity, p. 153-182. In: C.M. Menzel and G.K. Waite (eds.). Litchi and longan: Botany, production and uses. CABI, Wallingford, UK.

Mustard, M.J., S.Y. Liu, and R.O. Nelson. 1953. Observation of floral biology and fruit setting in litchi varieties. Proc. Florida State Hort. Soc. 66:212-220.

Olesen, T., C.M. Menzel, N. Wiltshire, and C.A. McConchie. 2002. Flowering and shoot elongation of lychee in eastern Australia. Austral. J. Agr. Res. 53:977-983.

Pavel, E.W. and T.M. DeJong. 1993. Relative growth rate and its relationship to compositional changes of nonstructural carbohydrates in the mesocarp of developing peach fruit. J. Amer. Soc. Hort. Sci. 118:503-508.

Roe, D.J., C.M. Menzel, J.H. Oosthuizen, and V.J. Doogan. 1997. Effects of current $\mathrm{CO}_{2}$ assimilation and stored reserves on litchi fruit growth. J. Hort. Sci. 72:397-405.

SAS Institute. 1996. SAS Software release 6.12. SAS Inst. Inc., Cary, NC.

Stern, R.A. and S. Gazit. 2003. The reproductive biology of the lychee. Hort. Rev. 28:393-453.

Subhadrabandhu, S. and R.A. Stern. 2005. Taxonomy, botany and plant development, p. 25-34. In: C.M. Menzel and G.K. Waite (eds.). Litchi and longan: Botany, production and uses. CABI, Wallingford, UK.

Teng, Y.S. 1997. Cultivation experiment of lychee (Litchi chinensis Sonn.) cv. Yu Her Pau, p. 93-96. In: L.J. Chang and R.W. Chen (eds.). Special report: Proceedings of a symposium on enhancing competitiveness of fruit industry II. Taichung District Agricultural Improvement Station, Chunghua, Taiwan (in Chinese with English summary).

Yen, C.R., Y.W. Liao, and Y.J. Tien. 1984. The cultivars of litchi (Litchi chinensis Sonn.) and their improvement in Taiwan. J. Chinese Soc. Hort. Sci. 30:210-222. (in Chinese with English summary).

Yen, C.R. and Y.J. Tien. 1985. Effect of pruning on the growth and yield of litchi. 1. Effect of harvest pruning on the flushing and flowering in varieties of different vigor. J. Chinese Soc. Hort. Sci. 31:40-43. (in Chinese with English summary).

Yuan, R. and H. Huang. 1988. Litchi fruit abscission: Its pattern, effects of shading and relation to endogenous abscisic acid. Scientia Hort. 36:281-292.

Yuan, R. and H. Huang. 1993. Regulation of root and shoot growth and fruit-drop of young litchi trees by trunk girdling in view of sourcesink relationships. J. Fruit Sci. 10:195-198. (in Chinese with English summary). 